\title{
Algunas reflexiones más sobre una cuestión espinosa: la responsabilidad social de las empresas
}

\author{
JEAN-MICHEL SERVAIS*
}

\section{SUMARIO: I. LOS CÓDIGOS Y LOS CERTIFICADOS DE BUEN COMPORTA- MIENTO.- II. EL PAPEL DE LAS INSTITUCIONES PÚBLICAS, INTERNACIONA- LES Y NACIONALES.- III. OBSERVACIONES FINALES.}

Ver como una prioridad que su empresa ofrezca buenas condiciones de empleo no constituye evidentemente una política novedosa. Fue por ejemplo una preocupación esencial de agrupaciones de empresarios cristianos o de personalidades racionalistas. El paternalismo ha existido desde el siglo XIX. En el principio de la revolución industrial, la historia ha retenido, entre otros, los nombres de Daniel le Grand en Francia o de Charles Hindley en Gran Bretaña. Siempre, sin embargo, se ha subrayado fuertemente la acción social de las empresas, durante períodos de incertidumbre, sobre la capacidad de los Estados, y de sus instrumentos jurídicos, de proteger adecuadamente la mujer y el hombre que trabajan.

Debilitando el poder reglamentario de las naciones, la internacionalización acelerada de la producción económica y del comercio ha de nuevo evidenciado estas prácticas, en particular — pero no solamente- las iniciativas que han adoptado las firmas transnacionales. El papel más discreto de los poderes públicos también ha empujado a los sindicatos y a otras organizaciones no gubernamentales a insistir sobre la responsabilidad social de las empresas (RSE): se ha pedido que justifiquen su gestión igualmente ante este punto de vista, es decir, que den cuenta de las consecuencias de sus actividades sobre la cualidad de vida a la vez de sus asalariados y de la comunidad local dentro de la cual se han instalado. Existe literatura abundante sobre el tema ${ }^{1}$.

Es profesor invitado en las Universidades de Gerona y Lieja, presidente honorario de la Sociedad Internacional de Derecho del Trabajo y de la Seguridad Social, y ex director en la Oficina Internacional del Trabajo.

1 Además de las publicaciones citadas en las páginas siguientes, mencionemos estas: «Responsabilidad social de las empresas transnacionales: análisis critico y prospectiva jurídica». Cuadernos de Relaciones Laborales, №1, vol. 27, 2009, pp. 93-123; DAUGAREILH, I. De l'irresponsabilité à la responsabilité sociale des enterprises. Bruselas: Bruylant, en prensa; JAVILLIER, J.C. et al. Governance, international law and corporate social responsibility. Ginebra: OIT/IIES, 2008; CAMPA, L. «Corporate social responsability and workers' rights». Comparative Labor Law and Policy Journal, vol. 30 (1), otoño de 2008, pp. 1-10; MOREAU, M.A. y FRANCIONI, F.(directores). La direction pluridisciplinaire de la responsabilité sociale de l'entreprise. Marsella: PUAM, 2007; AUVERGNON, Ph. (director). Quelle responsabilité sociale pour l'entreprise? Approches juridiques nationales et comparatives. Burdeos: Comptrasec/Université Montesquieu-Bordeaux IV, 2005; BLANPAIN, R. «The role of codes of conduct in monitoring multinational corporate behaviour ». En R. Blanpain y B. Flodgren, B. (directores). Corporate and Employment 
Por cierto, a muchos empresarios, no les importa únicamente el éxito en el marco de la economía de mercado. Sienten una responsabilidad de cara a la res pública: si por un lado dependen de un entorno político y social ordenado y estable, por el otro son a menudo conscientes de su dinamismo y de su capacidad creativa para activar la sociedad y las metas políticas a largo plazo años. Por ejemplo, Reinhard Mohn, el fundador del poderoso grupo editorial Bertelsmann, parecía asumir tal responsabilidad ${ }^{2}$ que vale más llamar «societal» cuando se extiende no solo al personal, sino también a la «cosa pública». En breve consideran que tienen que estar dispuestos a tener en cuenta las consecuencias de su estrategia sobre sus trabajadores, la sociedad y el medio ambiente ${ }^{3}$.

Esta responsabilidad se funda por consiguiente sobre bases éticas y sociales incontestables, es decir, sobre la preocupación de los empleadores de respetar y promover reglas cívicas en sus relaciones con sus trabajadores, los vecinos y las autoridades locales o nacionales. De hecho, se apoya igualmente sobre la constatación de que buenas condiciones de empleo estimulan el rendimiento ${ }^{4}$. Corresponde finalmente a la voluntad de conservar y de ofrecer al público una reputación excelente que no ha sido manchada por la utilización de métodos de producción que provocan la reprobación; la experiencia ha demostrado que una conducta tal incluso arriesgaría provocar campañas de prensa y de boicot lanzadas por organizaciones de trabajadores, asociaciones de consumidores $\mathrm{u}$ otros grupos sociales.

Los objetivos que acabamos de identificar explican probablemente las numerosas controversias que la cuestión suscita y la impresión de desorden que rodea el debate 5 . En estas condiciones, no parece inútil, al principio del presente artículo, que recuerde algunos principios básicos; la precaución es poco necesaria para una mayoría de lectores, pero aparece seguramente indispensable para otros que se sienten demasiado confiados en las posibilidades de estas iniciativas de compensar las insuficiencias de los Derechos nacionales del trabajo y de las normas de la OIT.

¿Cómo podemos analizarlas, en primer lugar, desde un punto de vista jurídico? La respuesta exige sin duda que reflexionemos sobre la noción

Perspectives in a Global Business Environment. Bulletin of Comparative Labour Relations, № 60, 2006, pp. 144-161, La Haya; HEPPLE, B. «A race to the top? International investment guidelines and corporate codes of conduct». Comparative Labor Law and Policy Journal, vol. 20, 1999, pp. 347-363; SoBCZAK, A. Réseaux de sociétés et codes de conduite. Un nouveu modèle de régulation des relations de travail pour les entreprises européennes. París: LGDJ, 2002; RoGosky, N. y E. SIMS. Corporate success through people: making international labour standards work for you. Ginebra: OIT, 2002.

2 Véase el homenaje fúnebre de R. Díez Hochleitner a Reinhard Mohn en El País del 5 de octubre de 2009, p. 40.

3 Véase, por ejemplo, IgALENS J. y S. POINT. Vers une nouvelles gouvernance des entreprise: l'entreprise face à ses parties prenantes. París: Dunod, 2009.

4 Véase aún recientemente MEYER-BISCH, P., J.J. FRIBOULET y E. DAVOINE (directores). L'effectivité des normes sociales internationales dans l'activité économique. Bruselas, Bruylant, París: LGDJ y Zúrich, Schultess, 2008.

5 Véase igualmente NEAL, A. "Corporate social responsibility: governance, gain or laissez-faire fig leaf ?». Comparative Labour Law and Policy Journal, vol. 29 (4), verano de 2008, pp. 459-474. 
misma de «Derecho». Definiendo la regla jurídica por referencia al apremio, podemos considerar que impone una conducta bajo la amenaza de sanción en caso de violación. En cambio, las otras técnicas de implementación de políticas sociales recurren principalmente a la razón y a la persuasión. Estas últimas incluyen la conclusión de pactos políticos, la adopción de medidas económicas, la organización de campañas de formación y de información, así como la elaboración de «normas» técnicas - pero no jurídicas - y de directrices prácticas. Pueden realizarse sin que se utilicen medidas con alcance jurídico. La calificación de soft-law recela una ambigüedad cierta en estas hipótesis porque no contienen los atributos del Derecho.

Observar ello no significa que se desprecie la utilidad de tales acciones y declaraciones, su capacidad de convencer. Invocar valores, fijarse objetivos sociales en la preparación de una política y en su aplicación parece eminentemente razonable y deseable. No obstante, la afirmación de «derechos» morales no confiere automáticamente una fuerza imperativa a las reglas de natura pública adoptadas por los Estados o a las normas de natura privadas elaboradas por las empresas. Proclamar una interdicción del trabajo infantil sin adjuntar una amenaza de sanción en caso de inejecución corresponde a la expresión de una esperanza, de un mensaje político por seguro importante pero sin alcance jurídico. No se debe subestimar su repercusión, pero sí destacarse su carácter circunstancial. El empleo de medios jurídicos asienta un designio a más largo plazo que entraña la voluntad de dar duración a tal política mediante su consagración en diversos textos y de recurrir, cuando sea necesario, a la sanción propia del Derecho. Sin embargo, sabemos que el entorno socioeconómico impide en muchos casos imponer sanciones que asegurarían permanencia y coerción a la interdicción.

Recordar que las sociedades mercantiles, sea cual sea su talla y su poder financiero, no son sujetos de Derecho internacional público parece una evidencia. Los Derechos nacionales del trabajo rigen sus relaciones con su personal y con los sindicatos. Sin embargo, se mantiene a veces la confusión en el caso de las grandes firmas que compiten con los Estados en términos de influencia y de capacidades de decisión.

Extender la competencia de instrumentos obligatorios de la OIT, de la ONU o de la OCDE a empresas y otras entidades globalizadas de natura privada enfrentaría además dificultades particulares. Ya muchas discrepancias se observan en la aplicación a los Estados de los convenios internacionales del trabajo. En primer lugar, las naciones conservan la libertad de comprometerse o no, a través de la ratificación, a respetar normas, incluso fundamentales, de las organizaciones internacionales. Los obstáculos conciernen igualmente a la imprecisión de ciertas obligaciones contenidas en los instrumentos - $-\mathrm{y}$ si constituyen obligaciones de resultado o únicamente de medio-, a los problemas encontrados para controlarlos y para sancionar los contraventores, como ocurre

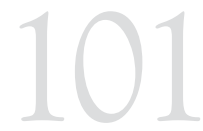

ALGUNAS REFLEXIONES MÁS SOBRE UNA CUESTIÓN ESPINOSA: LA RESPONSABILIDAD SOCIAL DE LAS EMPRESAS 
actualmente en el caso de Myanmar ${ }^{6}$. Se relacionan también al entorno socioeconómico y cultural en el cual se integran - como queda evidenciado en la economía informal de muchos países en vía de desarrollo-, a la debilidad de las estructuras institucionales de varios Estados e interlocutores sociales, así como a la visión que la gente tiene del Derecho, del trabajo y de las relaciones laborales en diferentes partes del mundo.

Más allá de eso, la norma de Derecho internacional solamente produce efectos cuando la situación presenta un elemento de extranjería, que no existe siempre en lo que concierne la RSE.

Las reglas de responsabilidad social se limitan a veces a inspirar la política de recursos humanos de las empresas. Otras veces poseen un real valor imperativo, aunque no es fácil descubrirlo. Repitamos que las violaciones solo son pasibles de las sanciones previstas por los Derechos nacionales y no por convenios internacionales: hasta ahora, estos últimos han creado obligaciones para los Estados o para las organizaciones internacionales, mas no para las personas físicas o jurídicas privadas.

Ir más allá de estas dificultades exige esfuerzos, imaginación y paciencia: esfuerzos, para quedar suficientemente claro y preciso; imaginación, para animar a las asociaciones empresariales y sindicales, incluso a otras organizaciones no gubernamentales, a elaborar entre ellas una primera regulación cuando los Estados sean incapaces de hacerlo; paciencia, para aceptar, al menos hasta el momento, normas que poseen un limitado o inexistente carácter obligatorio.

Los códigos de conducta, el etiquetado de calidad, los certificados de buen comportamiento social y las fórmulas equivalentes adoptadas por las firmas para afirmar su responsabilidad social aparecen en estas condiciones como bienvenidas. Completan los Derechos nacionales del trabajo y el Derecho de la OIT, e incluso los mejoran sin substituirlos o transformarlos.

Algunos se interrogan sobre la posibilidad de votar a favor de nuevas normas internacionales para crear un cuadro jurídico supranacional e imponer a los Estados la especificación de su contenido, su valor imperativo, los procedimientos de control. Sin duda la hipótesis es deseable. Sin embargo, es muy improbable en el estado presente del concierto de las naciones. En cambio, parece más realista y muy necesario llamar a una mejor articulación de las reglas transnacionales de Derecho privado y público, adoptadas por instituciones de todas naturas, cuya abundancia da la impresión de desorden y perjudica la efectividad.

No existe una definición unánime de la RSE. No obstante, es generalmente admitido que el concepto se refiere a prácticas bastante variadas que las firmas ponen en marcha de forma voluntaria y que sobrepasan 
las obligaciones legales a las cuales deben obedecer. Conciernen al rechazo de métodos financieros condenables y a la corrupción, al respeto de los derechos humanos, a la integración dentro de las comunidades locales o a la preservación del medio ambiente, tanto como a la gestión del personal, a las condiciones de empleo y a las relaciones laborales? sobre las cuales concentraremos nuestra atención.

Ciertas firmas se comprometen a respetar reglas mínimas de trabajo en los contratos mercantiles que firman con sus proveedores, subcontratistas, concesionarios o clientes; más a menudo —una posibilidad no impide la otra - lo hacen dentro del cuadro de la empresa o del grupo en documentos que se suman al reglamento del establecimiento. Estas medidas han frecuentemente recibido la denominación genérica de «códigos de conducta». Las sociedades privadas también pueden obtener certificados de buena honorabilidad social por parte de una autoridad exterior. Los dos tipos de iniciativas a veces coexisten. Las unas y las otras constituirán el objeto de la primera sección de este artículo. En la segunda, evocaré el papel desempeñado por las instituciones internacionales y algunos gobiernos para promoverlas, antes de expresar algunas reflexiones finales.

\section{LOS CÓDIGOS Y LOS CERTIFICADOS DE BUEN COMPORTAMIENTO}

\section{A. Los códigos de conducta}

El código de conducta, sea cual sea su nombre, contiene compromisos que una empresa acata voluntariamente, es decir, sin estar jurídicamente obligada a hacerlo. El documento puede tener la forma de un convenio colectivo firmado con un sindicato. Puede también resultar de un acuerdo con organizaciones no gubernamentales. En la mayoría de los casos, sin embargo, se materializa como una decisión unilateral de la empresa, como una declaración pública o como un añadido, por parte de la dirección, al reglamento de la empresa.

Cada vez se deben determinar las reglas aplicables. Cuando la empresa posee establecimientos en más de un país, el régimen legal de un contrato o de un acuerdo colectivo depende de la ley, o de las leyes aplicables, cuestión del Derecho internacional privado o, llegado el caso, del Derecho europeo. Los compromisos unilaterales de la compañía no tienen efectos jurídicos claros. En muchos casos, se puede considerar que no están legalmente obligadas a seguirlos, porque la dirección no tenía la intención cierta de «obligarse» a hacerlo. En otros, la regla aplicable puede provenir de la legislación sobre los reglamentos de empresa, del Derecho de los contratos, de la responsabilidad civil delictiva o incluso 
del Derecho de las sociedades comerciales. Tampoco es fácil aportar la prueba precisa del valor legal para el compromiso.

No obstante, más y más jueces condenan empresas que no respetan su código de conducta y que se apoyan sobre figuras jurídicas conocidas. En efecto, las legislaciones civiles inspiradas en el Código de Napoleón reconocen efectos jurídicos al compromiso unilateral; otras consideran que se integra legalmente a los contratos de empleo que no lo contradicen; en los Estados Unidos, tribunales admiten la responsabilidad de la firma por publicidad falsa. Cabe notar que el empleador puede tener una responsabilidad jurídica previa al código de conducta, como en materia de perjuicios vecindarios, de accidentes laborales y de enfermedades profesionales o de discriminación en el empleo. El documento sigue ahora poniendo en práctica una obligación legal preexistente.

Ciertos códigos solamente conciernen las actividades de una firma, sea dentro de un país o en el extranjero. Otros cubren los colaboradores comerciales, sobre todo los proveedores y los subcontratistas, como ocurre a menudo en los sectores textil, de calzado, agroalimentario y en agricultura. En cambio, tratan especialmente de las operaciones de la compañía y de sus colaboradores financieros en ramas de actividad como la ingeniería mecánica o eléctrica, las minas, la metalurgia, la química o las finanzas. Muchos documentos adoptados a la iniciativa de varias partes interesan únicamente a las relaciones con los proveedores y los subcontratistas; la mayoría de los debates sobre el control de las prácticas de trabajo se concentran en este tipo de acción. Su formulación no permite siempre saber si los códigos que rigen las cadenas de suministro llevan realmente un modo de regulación totalmente nuevo o si intentan solamente consolidar el respeto de disposiciones nacionales e internacionales en vigor 8 .

La OIT ha establecido una base de datos llamada BASI (Business and Social Initiatives Data Base), que contiene información sobre un número significativo de iniciativas 9 . Su análisis permite diferenciar los códigos «operacionales» de los «códigos tipos» publicados por asociaciones empresariales, sindicatos, ONG y Estados, sea juntos, sea por separado, que no se aplican como tal, sino que sirven a las firmas nacionales y supranacionales para poner a punto su propio código ${ }^{10}$.

\section{Códigos tipos y normas de gestión}

Se encuentran dentro de esta categoría las «normas» de gestión (management framework) redactadas por varios tipos de grupos. En términos generales, estas normas animan a las empresas a adoptar métodos de

8 Documento GB.288/WP/SDG/3, óp. cit., § 5.

9 Véase $<w w w$.ilo.org/basi>.

10 Documento del Consejo de Administración de la OIT GB.273/WP/SDL/1, Ginebra, 1998, §§ 33 y siguientes. 
gestión propicios para evaluar sus actividades en lo que concierne a su responsabilidad social. Se pueden distinguir dos clases ${ }^{11}$.

Las primeras, promovidas por ONG, autoridades públicas y consultores, pretenden materializar el compromiso social de diferentes partes interesadas junto con la compañía. Crean un cuadro que debe ayudarlas a asegurar su seguimiento, al fijar objetivos, identificar indicadores y seguir procedimientos de informes para garantizar la eficacia del sistema.

Las segundas están elaboradas por instituciones privadas o públicas. La figura más conocida es la del modelo ISO (International Organization for Standardization), en materia de normas de calidad y de medio ambiente. En materia social, la norma ISO precisa las medidas preventivas y correctivas que se deben adoptar, favorece los mejoramientos continuos, y se concentra sobre los sistemas de gestión y de documentación que demuestran ser eficaces en cuanto a los métodos elegidos. ISO esta elaborando un guía de orientación sobre RSE: la ISO 26000. La OIT, la Organización Internacional de los Empresarios (OIE) y la Confederación Sindical Internacional (CSI) participan en su trabajo. El proyecto integra la Declaración de Principios Tripartita de la OIT sobre las Empresas Internacionales y la Política Social, así como otra relativa a los principios y a los derechos fundamentales al trabajo ${ }^{12}$, además de normas internacionales del trabajo sobre la promoción del empleo, el respeto de los derechos de los trabajadores y varios cuestiones más amplias de desarrollo económico y social ${ }^{13}$.

El Pacto Mundial de la ONU, con su rendimiento modelo, constituye otro ejemplo de este enfoque.

No se necesita hacer hincapié en la importancia y en la utilidad de estos instrumentos de gestión. Más bien, debe temerse que, para muchos políticos y empresarios, puedan sustituir las más precisas y detalladas normas de la OIT, que cubren, además, prácticamente todas las materias del Derecho del trabajo y de la seguridad social.

\section{Códigos operacionales}

Contrariamente a los precedentes, los códigos operacionales contienen un compromiso de las empresas - y posiblemente de otras partes - para adoptar una conducta determinada. Una reseña de su contenido revela que las referencias a las normas fundamentales del trabajo (ausencia de discriminación en el empleo, interdicción del trabajo forzoso e infantil, libertad sindical y libre negociación colectiva) parecen poco frecuentes ${ }^{14}$. Los documentos tratan más, en lo que concierne al trabajo, acerca 
de la protección de la salud, o incluso del cálculo de los salarios, basados, según el caso, sobre la legislación nacional, las reglas sectoriales o una fórmula propia. Cuando la iniciativa procede de varias partes interesadas (sindicatos, asociaciones industriales o de empresas, ONG), disposiciones fundamentales están mencionadas más a menudo.

La credibilidad de los códigos de empresas depende no solamente de su contenido y de su fuerza obligatoria, sino también de la calidad de los controles efectuados para verificar la aplicación efectiva de los compromisos tomados, especialmente en vista de las incertidumbres que se relacionan con su valor jurídico.

Es interesante observar que los acuerdos concluidos entre firmas multinacionales y federaciones sindicales crean, en principio, procedimientos de supervisión. Constituyen, en su mayoría, mecanismos de concertación, de sensibilización y de quejas que prolongan a nivel global las instituciones de relaciones laborales establecidas tradicionalmente en los niveles nacional, sectorial y de empresa. Estos convenios colectivos transnacionales prevén que los dirigentes de la empresa, los ejecutivos y los representantes de los asalariados se reúnan a fin de examinar su implementación. A veces imponen obligaciones más específicas: difundir el acuerdo y, llegado el caso, traducirlo; elaborar programas conjuntos de formación, etcétera. El control del respeto de sus disposiciones a menudo corresponde, en primer lugar, a los responsables locales de la compañía y de los sindicatos; ante dificultades, existen procedimientos de solución a niveles más altos. Frecuentemente, los acuerdos mencionan el Convenio 135 de la OIT relativo a los representantes de los trabajadores, que data de $1971^{15}$.

Los códigos de conducta que son elaborados de otra forma organizan también, más y más, mecanismos de vigilancia, internos o externos, los segundos muchas veces completando los primeros. Sin embargo, los procedimientos de verificación, incluso los dirigidos por organismos exteriores a la compañía, suscitan problemas complejos. Conciernen a la competencia y a la independencia de los inspectores que provienen de instituciones privadas, elegidas y pagadas por la empresa, así como a la duración y al objeto de las auditorias. Tratan incluso sobre el carácter más o menos preciso y verificable de las cláusulas contenidas en los documentos $^{16}$.

Estos aparecen, por consiguiente, como garantías útiles del trabajo que complementan las legislaciones laborales y que se han redactado especialmente en situaciones en las cuales el Derecho social no cubre todas 
las categorías de asalariados o no está suficientemente aplicado. La observación vale para muchos países y para las relaciones laborales internacionales. Los códigos de conducta igualmente contribuyen, aunque de manera limitada, a la implementación de las normas de la OIT ${ }^{17}$, en el sentido de que puedan concretar algunas disposiciones tomadas por la organización en las firmas consideradas. La diversidad de esos documentos resulta, de otro lado, en una debilidad, pues no existe coherencia en los principios que consagran. Otras limitaciones conciernen a su campo de aplicación. Las firmas que los adoptan operan esencialmente en los sectores estructurados y no, en todo caso directamente, en la economía informal, donde trabajan un número considerable de personas de los países en vías de desarrollo.

Encontramos aquí una razón suplementaria para extender su efectividad a los subcontratistas, que a menudo utilizan la mano de obra desempleada de las zonas más pobres de la ciudad y el campo. Las compañías más poderosas son las más dispuestas, como ya hemos subrayado, a seguir esta política a fin de defender su imagen de marca, en vista de que también están más en la mira de campañas mediáticas hostiles ${ }^{18}$.

\section{B. Etiquetado y otros certificados de buena política social}

\section{Etiquetado social}

El «sello social» constituye una forma de comunicar informaciones sobre las condiciones sociales que están envueltas en la fabricación de un producto o en la prestación de un servicio. Algunas veces figura sobre el propio objeto o sobre su embalaje. Otras veces los comercios lo muestran en su tienda o en su escaparate. Se dirige a los consumidores o a los colaboradores comerciales y corresponden a una lógica de mercado ${ }^{19}$.

Si una firma, uno de sus productos o uno de sus servicios adquiriese cierta notoriedad basada en su código de conducta, su nombre o su marca constituirían una denominación preciosa. A veces ocurre incluso que las empresas conceden su explotación, a través de una licencia, a subcontratistas, franquicias y concesionarios que cumplen criterios preestablecidos $^{20}$. Podemos repetir, en este caso, lo que hemos dicho para los códigos de conducta.

En cambio, otro etiquetado procede de autoridades o instituciones independientes, que los elaboran y los controlan. Son asociaciones empresa-

17 Somavía, J. Un trabajo decente. Informe del Director General de la OIT a la $87^{a}$ sesión de la Conferencia Internacional del Trabajo. Ginebra: OIT, 1999, p. 22; COMISIÓN MUNDIAL SOBRE LA DIMENSIÓN SOCIAL DE LA GLOBALIZACIÓN. Por una globalización justa: crear oportunidades para todos. Ginebra: OIT, 2004, §§ 550-559.

18 FLANAGAN y GOULD (directores). International labor standards... Óp. cit., p. 10

19 Documento GB.273/WP/SDL/1, óp. cit., § 68.

20 DilleR, J. «¿Una conciencia social en el mercado mundial?: dimensiones laborales de los códigos de conducta, el etiquetado social y iniciativas de los inversores». Revista Internacional del Trabajo, vol. 118 (2), 1999.

ALGUNAS

FLEXIONES MÁS

SOBRE UNA CUES-

TIÓN ESPINOSA:

LA RESPONSABI-

LIDAD SOCIAL DE LAS EMPRESAS 
riales que garantizan el respeto de un código de conducta, sindicatos que responden de esta manera a la buena aplicación de un programa social, ONG u otras agrupaciones que certifican la correcta implementación, por parte de la firma beneficiaria, de una política conforme con indicadores seleccionados, incluso en la ausencia de un código de conducta.

\section{Programas de acreditación y de certificación}

Los programas de acreditación y de certificación constituyen hoy día prácticas corrientes. La mayoría son administrados por una institución principal que aprueba otros organismos como agencias de notación. $\mathrm{Nu}-$ merosos ejemplos se encuentran en sectores variados (textil, calzado, industria ligera, alfombra, fabricación de juguetes, turismo, agricultura, agroalimentario, industria forestal). Los programas se apoyan sobre criterios o normas de carácter privado, que conciernen, entre otros elementos, a las relaciones laborales y a las condiciones de trabajo. A veces se refieren a los instrumentos de la OIT, incluso a su declaración de 1998 relativa a los principios y a los derechos fundamentales al trabajo ${ }^{21}$, aunque lo hacen de forma selectiva.

Las normas sobre las cuales la observación resulta comúnmente más controlada conciernen la ausencia de discriminación y de trabajo forzoso u infantil, la libertad de asociación y la negociación colectiva, el acoso y el comportamiento abusivo, la seguridad y la salud en el trabajo, los salarios y las prestaciones sociales, y los horarios de trabajo ${ }^{22}$. Cabe notar que son más extendidas que los códigos de conducta.

Inspecciones y auditorías son organizadas por grandes gabinetes internacionales de contables acreditados y de consultores, por oficinas más pequeñas, por empresas especializadas en el control de la calidad, por universitarios, por sindicatos o por $\mathrm{ONG}$, establecidos en países industrializados o no, varios de los cuales llegan a participar conjuntamente en la supervisión. Las investigaciones se realizan, la mayoría de las veces, a través de visitas sobre el sitio, incluidos un examen de los documentos de la empresa y entrevistas con sus dirigentes, personal y delegados, incluso posiblemente con representantes de la sociedad civil. A veces comprenden discusiones conducidas con grupos informales, así como una evaluación de los riesgos a los cuales se exponen los trabajadores para su salud y su seguridad. Sin embargo, los métodos de vigilancia adoptados todavía aparecen, en muchos casos, en una fase muy preliminar de elaboración ${ }^{23}$.

\section{Los informes sociales}

La preparación de informes sobre las repercusiones sociales y medioambientales de sus actividades constituye otra iniciativa hoy bastante

21 La declaración se refiere a la libertad sindical, a la libre negociación colectiva, a la abolición del trabajo forzoso e infantil, y a la eliminación de las discriminaciones profesionales.

22 Documento GB.288/WP/SDG/3, óp. cit., §§ 9-13.

23 lbíd., §§ 13 y 14. 
habitual en muchas empresas multinacionales y nacionales. El personal y sus evoluciones, así como los salarios, son las cuestiones que resultan más examinadas en estos documentos; vienen después la formación, la higiene y la seguridad. Entre los temas de derechos fundamentales en el trabajo, la primacía corresponde a la igualdad de oportunidades y a la ausencia de discriminación, pero muy detrás de los puntos ya mencionados $^{24}$.

La Global Reporting Initiative (GRI) parece bien haber creado el sistema más conocido. Intenta mejorar la posibilidad de comparar y la credibilidad de este tipo de documentos. Compañías, incluso gabinetes de contables acreditados, sindicatos, ONG, asociaciones ecologistas o de defensa de los derechos humanos han participado en su concepción. Tiene como objetivo poner a punto normas ampliamente aceptadas y reconocidas, análogas a las reglas elegidas para la preparación de los informes financieros.

El sistema GRI presenta indicadores sobre las condiciones de empleo en su apartado «Indicadores de rendimientos sociales: prácticas en materia de relaciones laborales y trabajo decente». La referencia al «trabajo decente» se remite a los trabajos de la OIT, la cual utiliza, como se sabe, el concepto para expresar la síntesis de sus actividades y la coordinación de sus miras estratégicas ${ }^{25}$. Las herramientas de evaluación conciernen el empleo, las relaciones colectivas, la higiene y la seguridad en el trabajo, la formación, la diversidad y la igualdad de oportunidades. Hacen referencia a la Declaración de Principios Tripartita de la OIT sobre las Empresas Internacionales y la Política Social, así como a las directrices de la OCDE dedicadas a las empresas multinacionales ${ }^{26}$.

El sistema contiene otros indicadores en el apartado «Indicadores de rendimientos sociales: derechos humanos», donde se mencionan los convenios fundamentales de la OIT y la Declaración Universal de los Derechos Humanos. Debe destacarse que se refieren solamente a estos documentos en lugar de a otros adoptados por las Naciones Unidas y que poseen una fuerza obligatoria a partir de la ratificación: en particular, los dos pactos de 1966 sobre los derechos civiles y políticos, de un lado, y el de los derechos económicos, sociales y culturales, del otro.

Precisemos, no obstante, que estos indicadores conciernen a la ausencia de discriminación, a la libertad de asociación y a la negociación colectiva, a la abolición del trabajo forzoso e infantil, a las prácticas disciplinarias, a las medidas de seguridad, así como a los derechos de las poblaciones locales. Hacen mención a los convenios de la OIT número 29 sobre el trabajo forzoso y número 138 sobre la edad mínima, así como al repertorio de recomendaciones prácticas de la organización sobre los 
sistemas de gestión de la seguridad y de la salud en el trabajo. De todos modos, algunos de los elementos que el GRI trata de medir resultan muy difíciles cuantificar y las conclusiones pueden, por consiguiente, carecer de significación ${ }^{27}$.

El estudio de sus modalidades pone en evidencia, una vez más, que estas iniciativas aparecen sin duda como complementos útiles de la acción normativa internacional. No poseen un carácter coherente, sistemático y global, que les permita tener una influencia significativa y durable a nivel universal. La decisión de países coma Bélgica o Francia de imponer a las sociedades que tienen una cierta dimensión de elaborar un informe sobre algunos aspectos de las condiciones de empleo podría mejorar la situación.

\section{Las inversiones socialmente responsables}

La ética social de inversiones intenta favorecer las buenas políticas sociales de empresas, para lo cual se emplean herramientas financieras tradicionales como el establecimiento de índices y técnicas de la notación, mientras preservan el rendimiento económico de las aportaciones. Utiliza dos medios principales de acción ${ }^{28}$. El primero consiste en la facultad de los inversores de tener en cuenta las realizaciones sociales en la constitución de su cartera de valores; comprarán o no ciertos títulos basándose sobre los criterios o sobre las normas que han seleccionado. El segundo medio aprovecha la posibilidad de los accionistas de ejercer sus derechos para influenciar la política de la compañía. Estos medios se utilizan, por consiguiente, en momentos y en sentidos diferentes: el primero, antes de la compra de valores o al cambiarlos; el segundo, después de la entrada en el capital de la empresa. Un autor ha observado que las cajas de pensiones de la función pública y los fondos de las instituciones religiosas se muestran particularmente activos en este respecto ${ }^{29}$.

Los criterios y las normas seleccionados para decidirse sobre una inversión no aparecen más precisos o uniformes que en el caso de las iniciativas precedentes. Al margen de ello, algunas escalas recurren al conjunto de normas internacionales del trabajo; un estudio de la OIT menciona Calvert, Coreratings, EIRIS (Ethical Investment Research Service), PIRC (Pensions and Investment Research Consultants Ltd.) y Vigeo/ARESE. Otra agencia de notación, la SAM, pide a las firmas que suscriban públicamente la declaración de la OIT sobre las multinacionales; otras, como $\mathrm{KLD}$, repiten los puntos cubiertos por las normas fundamentales de la OIT sin referirse específicamente a los convenios de la organización ${ }^{30}$.

27 Documento GB.288/WP/SDG/3, §§ 23 y 24.

28 DilleR, J. «¿Una conciencia social en el mercado mundial?... Óp. cit.; G.L. CLARK y T. HebB. «Pension fund corporate engagement: the fifth stage of capitalism». Relations Industrielles/Industrial Relations, vol. 59 (1), invierno de 2004, pp. 142-171. 


\section{II.EL PAPEL DE LAS INSTITUCIONES PÚBLICAS, INTERNACIONALES Y NACIONALES}

Desde hace largo tiempo, las instituciones internacionales han calibrado bien el debate sobre la responsabilidad societal de las empresas y han establecido códigos de conducta dirigidos a inspirar sus políticas sociales. La OCDE, la OIT y más recientemente la ONU han redactado principios directores a este respecto. Otras instituciones internacionales y algunos gobiernos tratan igualmente de promover tales iniciativas.

\section{A. Las líneas directrices de la OCDE para empresas mul- tinacionales}

La OCDE adoptó, en 1976, una declaración sobre inversiones internacionales y empresas multinacionales. El documento, y las decisiones que han seguido, constituyen un compromiso político, tomado por los gobiernos de los Estados miembros, de mejorar el clima de las aportaciones extranjeras de fondos, de favorecer la contribución positiva de las multinacionales al progreso económico y social, y de resolver, o al menos reducir al mínimo, las dificultades que resultan de sus operaciones. Tanto la declaración como las decisiones adoptadas sobre su base son regularmente revisadas.

La declaración incluye directrices que tienen el carácter de recomendaciones sin valor obligatorio y que son dirigidas a las empresas por los gobiernos que las han suscrito. La observación de estas disposiciones es voluntaria y su aplicación es animada por puntos de contacto nacionales en los países miembros ${ }^{31}$.

Las directrices cubren el abanico de las actividades de las sociedades multinacionales y se apoyan sobre procedimientos de implementación en los países miembros, así como en algunos otros como Argentina, Brasil, Chile, Egipto, Eslovenia, Estonia, Israel, Letonia, Lituania, Perú y Rumania. Las completan comentarios explicativos y clarificaciones sobre su interpretación a continuación de las deliberaciones del Comité de las Inversiones Internacionales y de las Empresas Multinacionales.

El documento empieza con consideraciones generales sobre el respeto de los derechos humanos, sobre la importancia de la formación profesional, el cumplimiento de las reglas de la legislación nacional y sobre la información del personal. Siguen recomendaciones en muchas materias, tales como el medio ambiente, la lucha contra la corrupción, la publicación de informaciones, el interés de los consumidores, la competencia, la ciencia y la tecnología. En lo que concierne al empleo y las relaciones laborales, el instrumento se refiere a los derechos fundamentales en el

31 Véase <www.oecd.org/daf/investment/guidelines/mnetextf.htm>. También I. DAUGAREILH. «La dimension sociale des principes directeurs de l'OCDE à l'intention des entreprises multinationales". Revue Générale de Droit International Public, № 3, 2008, pp.567-599; TERGEIST, P. et al. «The Organisation for Economic Co-operation and Development». En R. Blanpain (director). International encyclopedia of labour law and industrial relations. La Haya: Kluwer, 1994.

ALGUNAS REFLEXIONES MÁS SOBRE UNA CUESTIÓN ESPINOSA: LA RESPONSABILIDAD SOCIAL DE LAS EMPRESAS 
trabajo consagrados por la OIT: ausencia de discriminación, abolición del trabajo forzoso e infantil, libertad sindical y libre negociación colectiva. Menciona explícitamente la declaración adoptada en 1998 por la organización sobre este tema.

Es muy claro con respecto a las relaciones colectivas, al pedir que los representantes de los trabajadores reciban toda la información necesaria y las facilidades para llevar a cabo las negociaciones. El texto se refiere expresamente a los cambios importantes que pueden ocurrir en la compañía, como el cierre de un establecimiento, y durante las discusiones colectivas condena las amenazas de transferir una o más entidades operacionales fuera del país. Cita también la salud y la seguridad en el trabajo. Sugiere finalmente que las firmas animan a sus colaboradores comerciales, incluso los proveedores y los subcontratistas, a aplicar reglas de comportamiento conformes con las líneas directrices.

Los comentarios que acompañan el documento se refieren a la Declaración Tripartita de la OIT sobre las Empresas Multinacionales y la Política Social. Precisan que las líneas directrices de la OCDE juegan un papel de promoción para que la otra declaración de la OIT, el instrumento de 1998, sea observada por las multinacionales. Subraya que tanto las directrices como la declaración de la OIT sobre las multinacionales conciernen al comportamiento esperado de las empresas. Al ser más detallada, la declaración de la OIT es «útil» para la buena comprensión de las directrices, aunque los procedimientos para seguirla no son de la competencia de los mismos órganos. Los comentarios señalan incluso los instrumentos de la OIT sobre la abolición del trabajo infantil (Convenios número 138 y 182; recomendación 146) y del trabajo forzoso (Convenios 29 y 105), la eliminación de la discriminación en el empleo y la profesión (Convenio 111), y sobre la consulta y la colaboración entre empleadores y asalariados al nivel de la empresa (recomendación 94).

\section{B. La Declaración de Principios Tripartita de la OIT sobre las Empresas Multinacionales y la Política Social} El desarrollo de las firmas transnacionales durante los años sesenta y setenta ha suscitado debates intensos en los foros internacionales, incluso en la OIT. La dificultad de reconciliar los puntos de vista descartó la posibilidad de redactar un convenio internacional sobre el tema. El Consejo de Administración de la organización optó en 1977 por una declaración, instrumento no obligatorio. Después de algunos párrafos explicativos y de políticas generales, el texto trata sucesivamente de cuestiones de empleo (seguridad y promoción del empleo, igualdad de oportunidades y de tratamiento, formación), de condiciones de trabajo y de vida (incluso prestaciones, edad mínima, salarios, seguridad y salud) y de relaciones colectivas (libertad sindical, negociación colectiva, consultas, examen de las reclamaciones y solución de los conflictos). El anexo presenta una lista de convenios y recomendaciones 
a los cuales el documento se refiere, método que permite subrayar la importancia de aquellos.

La declaración tiene por objeto fomentar la contribución positiva que las multinacionales pueden aportar al progreso económico y social, así como minimizar y resolver las dificultades a las que pueden dar lugar sus operaciones. Insiste sobre el carácter voluntario del documento que intenta guiar a los gobiernos y a las asociaciones empresariales y sindicales sin obligarlos a observar estos principios. Existe un procedimiento de informes, sin embargo, para evaluar el seguimiento del instrumento, y otro para examinar los conflictos surgidos sobre su aplicación ${ }^{32}$.

La OIT ha establecido programas específicos para promover la declaración. Más generalmente, pone en práctica actividades importantes en materia de responsabilidad social empresarial. Ha creado un servicio de asistencia para proporcionar asesoramiento especializado sobre la aplicación del texto y, más allá, de sus normas de trabajo. Ciertas peticiones vienen de agencias internacionales, como el Banco Mundial, o de autoridades nacionales, como USAID. La organización empuja la puesta en práctica de su instrumento no solo a través de proyectos de asistencia técnica realizados con gobiernos y asociaciones profesionales, sino también de colaboraciones de tipo «público-privado» con gobiernos y multinacionales, tales como Volkswagen y otras empresas transnacionales españolas. También recibe peticiones para suministrar informaciones técnicas sobre los aspectos sociales de los códigos de conducta. Actualmente, la oficina pone a prueba en el terreno nuevas modalidades para evaluar el curso de la declaración e imparte formación sobre su aplicación en colaboración con su centro de Turín. Trabaja estrechamente con otras organizaciones intergubernamentales que podrían contribuir a dar a conocer mejor su texto, en particular con la OCDE y la ONU ${ }^{33}$.

\section{El Pacto Mundial de las Naciones Unidas}

Las Naciones Unidas han elaborado más de una iniciativa para involucrar las grandes compañías nacionales y transnacionales en la defensa de los tratados universales sobre los derechos humanos. Ha lanzado en particular un Pacto Mundial (Global Compact), en julio de 2000, junto con varias otras organizaciones internacionales, incluso con la OIT. El instrumento es puramente voluntario. Pide a las empresas que hagan suyos, apoyen y lleven a la práctica una serie de valores fundamentales en materia de derechos humanos, normas laborales, medio ambiente y lucha contra la corrupción. Insiste sobre diez principios, de los cuales

32 Véase OIT. Declaración Tripartita de Principios sobre las Empresas Internacionales y la Política Social. Ginebra: 1977. También MoRgENSTERN, F. «Déclaration de principes tripartite sur les entreprises multinationales et la politique sociale. Nouveaux problèmes, nouvelles méthodes". Journal du Droit International (Clunet), № 1, 1983, pp. 61-75.

33 Documento del Consejo de Administración de la OIT GB.304 /MNE/1, Ginebra, 2009.

\section{ALGUNAS RE- \\ FLEXIONES MÁS \\ SOBRE UNA CUES- \\ TIÓN ESPINOSA: \\ LA RESPONSABI- \\ LIDAD SOCIAL DE \\ LAS EMPRESAS}


cuatro proceden de convenios de la OIT y de su declaración ya mencionada de $1998^{34}$.

Las firmas que se suman al pacto aceptan un compromiso individual de trabajar en la implementación de los diez principios. El documento cuenta con un conjunto de recursos y herramientas que proporcionan orientación a las empresas cuando deben tomar decisiones relacionadas con los principios. Una de las opciones se encuentra en un modelo preparado con el fin de transformar su visión en resultados. Ofrece a sus participantes diversas oportunidades para involucrarse en actividades que maximicen los beneficios y el valor de la participación (proyectos de colaboración, redes nacionales, reuniones y talleres en diferentes países, puesta en común de experiencias, acciones juntas).

Las empresas deben suministrar regularmente comunicaciones sobre los progresos para no ser excluidas de la lista del pacto. Los informes deben contener una confirmación de la adhesión a los principios referidos, una descripción de los medios concretos que han tomado para implementarlos y una medida de los resultados obtenidos y esperados.

Asimismo, se sugieren ciertos indicadores de realización. Se considera como un factor importante de progreso la implicación de participantes exteriores. Entre ellos son mencionados los representantes de la sociedad civil, de las organizaciones profesionales, de los gobiernos y de las instituciones internacionales, así como de las universidades. Pueden compartir conocimientos y experiencias, brindar consejos, pedir explicaciones, estimular ciertas actividades.

En breve, el pacto se ha hecho de un foro amplio que favorece el aprendizaje y el diálogo en materia de RSE.

\section{Iniciativa del Banco Mundial}

La International Finance Corporation (IFC), la sociedad financiera internacional del grupo del Banco Mundial, ha elaborado medios para facilitar la promoción de la empresa ciudadana y ayudar a sus clientes y al sector privado en los países emergentes a identificar posibilidades de inversión que le correspondan. Ha establecido un cuadro que permite medir la durabilidad de las inversiones privadas y que comprende una evaluación de la salud, de la seguridad y del bienestar de la mano de obra. Las decisiones que las firmas son invitadas a tomar al respecto incluyen la aplicación de los convenios de la OIT, el pago de un salario ligeramente más alto que el promedio y la observación del repertorio de recomendaciones prácticas de la OIT sobre el VIH/SIDA en el trabajo. El Instituto del Banco ha lanzado un curso en línea sobre la responsabilidad social de las empresas ${ }^{35}$. 
En octubre de 2008, la IFC publicó el informe anual Sustainability Business Innovator: Annual Report 2008, una plataforma dirigida a los gobiernos donantes, instituciones de desarrollo, la IFC misma y el sector privado. El documento somete a prueba la protección del medio ambiente y el desarrollo social, y demuestra su interés para el negocio; contiene varios ejemplos que ilustran cómo los empresarios pueden cambiar sus métodos y procesos para el beneficio de todas las partes interesadas ${ }^{36}$.

\section{E. Iniciativas europeas}

La Comisión Europea publicó en 2001 el Libro Verde sobre la responsabilidad social de las empresas ${ }^{37}$. Después de consultas y discusiones sobre el documento, redactó, en julio de 2002, una comunicación ${ }^{38}$ que reconoce su naturaleza voluntaria, subraya la necesidad de transparencia y de medidas creíbles e insiste sobre el valor de las actividades que involucren a comunidades locales. Fomenta una visión global de la cuestión, cubre sus dimensiones económicas, sociales y medioambientales, y toma en cuenta los intereses de los consumidores, las características propias de las PYMES, así como el respeto de los instrumentos internacionales entre los cuales destaca los textos que ya hemos mencionado. El texto tiene como objetivo favorecer el conocimiento de las buenas prácticas a través de varios medios: estimular y desarrollar las competencias en materia de gestión socialmente responsable, animar a las PYMES sobre el tema, favorecer la convergencia y la transparencia de las prácticas y de las herramientas respecto a eso, promover la cuestión dentro de la cooperación al desarrollo.

A semejanza de otras instituciones, la Unión Europea utiliza varios medios para promover las iniciativas de las cuales tratamos. La comisión lanzó en julio de 2002 un foro plurilateral europeo destinado a obtener una interpretación común del concepto, a alentarlo y a mejorar su credibilidad y eficacia, al proseguir con los objetivos económicos, sociales y medioambientales de la UE ${ }^{39}$. La plataforma está presidida por la Comisión Europea e integra empresas, sindicatos, ONG, inversores, consumidores y posiblemente otros actores interesados. Representantes de las Naciones Unidas, de la OIT y de la OCDE cuentan con estatuto de observadores. En noviembre de 2008, la comisión publicó un informe sobre la competitividad europea ${ }^{40}$ en el cual examina la vinculación entre esta y la RSE. En este respecto, ha anunciado que financiará iniciativas para investigar este vínculo en los sectores de química, textil y construcción, con énfasis en las PYMES. Estas acciones

ALGUNAS RE-

FLEXIONES MÁS

SOBRE UNA CUES-

TIÓN ESPINOSA:

LA RESPONSABI-

LIDAD SOCIAL DE LAS EMPRESAS 
implican varias partes, incluso asociaciones industriales, sindicatos, ONG y autoridades públicas.

Las organizaciones europeas de empresarios y de trabajadores de la restauración firmaron, en enero de 2007, un convenio colectivo innovador sobre la responsabilidad social de las empresas. El acuerdo establece una serie de normas mínimas voluntarias, concebidas como una fuente de inspiración y una base para discusiones ulteriores y que alientan a las asociaciones nacionales del sector y a sus miembros a elaborar códigos de conducta u otras iniciativas parecidas, con la participación de los representantes del personal y de los sindicatos. Cubre las cuestiones siguientes: derechos fundamentales, formación, salud y seguridad, seguridad alimentaría, diálogo social, igualdad de oportunidades y ausencia de discriminación, condiciones de empleo y organización del trabajo, salario decente, métodos para la adjudicación de contractos de restauración, reestructuración, relaciones de negocio y elección de los proveedores, lucha contra la obesidad. Las susodichas organizaciones deben invitar a sus miembros a propagar y discutir el acuerdo a nivel nacional, además de informarlos sobre ejemplos de buenas prácticas que serán analizados a fin de asegurar su seguimiento. El convenio colectivo cubre unos 600 mil trabajadores en Europa ${ }^{41}$.

\section{F. Iniciativas nacionales}

Varios Estados han adoptado medidas para promover una forma $\mathrm{u}$ otra de RSE. Las autoridades danesas, por ejemplo, han financiado la creación de un mecanismo de evaluación del impacto de los derechos humanos. Una base de datos éticos ha sido establecida en el Centro de Información para los Consumidores del Ministerio del Comercio; en esta, las empresas pueden indicar cómo aplican las normas reconocidas de trabajo.

El departamento británico y la agencia canadiense responsables del desarrollo internacional actúan juntos para la promoción de la RSE en su ámbito de competencia, en lo que concierne especialmente a las poblaciones desfavorecidas. El Reino Unido cuenta con un ministro encargado de esta cuestión dentro de su Departamento del Comercio y de la Industria. Su gobierno ha pedido a los gestores de fondos de pensiones británicos que registren la medida de factores sociales, medioambientales y éticos en su decisión de inversiones ${ }^{42}$. De similar modo, la ley francesa del 17 de julio de 2001 sobre los fondos de reserva de las pensiones pide a la junta directora que dé cuenta de las orientaciones sociales, medioambientales y éticas incluidas en la política de inversiones. 
Los gobiernos americanos y británicos han participado, junto con multinacionales y sindicatos, en la redacción de líneas directrices voluntarias para la industria del petróleo. En otros casos, la legislación misma ha tratado de estimular iniciativas sociales de las empresas. Una ley belga del 27 de febrero de 2002 creó un etiquetado que las empresas belgas y extranjeras puedan utilizar en la promoción de productos según determinados criterios y normas, que incluyen la observación de disposiciones contenidas en los convenios básicos de la OIT. En Francia, una ley del 15 de mayo de 2001 obliga a las sociedades cuyos títulos son admitidos en las negociaciones sobre un mercado reglamentado a que expliquen, en sus informes de gestión, de qué manera toman en cuenta las consecuencias medioambientales y sociales de sus actividades.

\section{OBSERVACIONES FINALES}

En el campo doctrinario, algunos ven fácilmente, dentro de la tendencia actual a insistir sobre la responsabilidad de los actores privados para la armonización de las relaciones sociales, la expresión de una visión liberal que antepone la iniciativa individual a la acción protectora de las autoridades públicas y de sus leyes. El argumento parece un poco ligero, especialmente cuando observamos que la problemática examinada no se limita a los temas sociales, sino que se extiende a cuestiones de derechos humanos en general, de medio ambiente y de relaciones con las comunidades locales. Lo hemos subrayado muchas veces.

En efecto, el proceso de mundialización ha hecho tambalearse, si no son más, numerosas instituciones establecidas en los Estados para organizar las relaciones entre individuos. Las redes creadas por los ciudadanos y sus dirigentes dentro de los cuadros nacionales no permiten ahora llevar las soluciones esperadas a los más agudos problemas actuales. Una mayoría se convence de que la acción concertada debe transferirse hacia el nivel regional — europeo o latino, por ejemplo- o mundial. Sin embargo, aún faltan órganos y canales de comunicación a esta escala ${ }^{43}$.

Las grandes compañías privadas tratan de colmar el vacío con las herramientas que poseen. Operan dentro de una esfera particular, con objetivos de rendimiento fijados por los órganos directores. Sin embargo, sus actividades en materia social no pueden reemplazar, sino constituir, un complemento útil a las políticas y a los programas de las autoridades públicas nacionales e internacionales.

Las limitaciones son de orden estratégico y de carácter técnico. Las primeras, de natura estratégica, traducen objetivos basados sobre una cierta política que son determinados por la dirección de la empresa, o al menos fijados con su aprobación. Se focalizan sobre los elementos que convergen entre los intereses de la compañía y los de su personal. Como

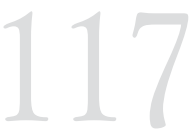

RESAS 
es sabido, no es siempre el caso; cuestiones en las cuales divergen las preocupaciones, como la precariedad del empleo, raramente se mencionan en los documentos concernidos.

De otra parte, sobre muchos puntos (la creación de empleos, la formación profesional, por ejemplo), las políticas sociales van más allá del cuadro de una firma particular, incluso en los países más liberales, por muy grandes que sean. Estas cuestiones normalmente no se reproducen tampoco en las iniciativas empresariales; excepciones existen, pero no son frecuentes. Cabe señalar, sin embargo, que más y más empresas de pronto manifiestan una afirmada voluntad a participar en programas de inserción o de reintegración social ${ }^{44}$, aunque incluso en estos casos no tratan de los problemas sociales generales de una comunidad local o de un país entero.

La difusión de estas prácticas también es desigual. En ciertas partes del mundo, y en ciertos sectores más que en otros, las firmas adoptan políticas dinámicas de desarrollo de los recursos humanos y obtienen, de esa manera, una ventaja frente a competidores activos. No desean necesariamente facilitar la imitación de las medidas tomadas por otras compañías; las guardan para sí mismas como secretos de fabricación. La Unión Europea ha tratado de introducir más transparencia en este campo, pero resulta difícil dar curso a sus llamamientos ${ }^{45}$.

Quizá por razones históricas, ciertas sociedades comerciales están dispuestas más que otras a asumir una responsabilidad determinada o son más capaces de hacerlo. A veces también existe el riesgo de que sus estrategias se desvíen de las políticas públicas y se opongan a los esfuerzos de los Estados para mejorar el régimen de trabajo, desarrollar el empleo, liberalizar los intercambios y distribuir equitativamente los frutos del crecimiento $^{46}$. En cualquier caso, las empresas de los países industrializados aún deben evitar que las decisiones sean tomadas por su junta directiva sin haber consultado sus filiales o subcontratistas en las naciones del sur y mientras no consideren con importancia suficiente sus escollos específicos, que proceden de la miseria y del subdesarrollo.

Limitaciones de tipo técnico se adjuntan a las estratégicas. Un primer obstáculo proviene de su ámbito de aplicación. La dificultad de implementar las normas nacionales o internacionales del trabajo a través de estas iniciativas es evidente: se relaciona con la cobertura reducida a una o varias empresas, a la duración de su validez y sobre todo a la medida de su carácter obligatorio. Por otro lado, no parece necesario subrayar que la adopción de estas iniciativas no permita a las firmas eximirse de la aplicación de la ley del país de acogida, incluso de los convenios internacionales integrados en su orden jurídico.

44 OIT. «Relaciones laborales, democracia y cohesión social». En El Trabajo en el mundo 1997-98. Ginebra: OIT, 1997, pp. 69 y 70.

45 Es verdad que la falta de transparencia de ciertas iniciativas puede tener otras causas y otros efectos. Se trata, en este caso, del valor de las políticas sociales efectivamente aplicadas.

46 DILLER. Óp. cit., p. 132. 
Los problemas técnicos en la implementación de cualquiera fórmula de responsabilidad social de empresa conciernen igualmente a las normas de trabajo seleccionadas y a su contenido. A mi conocimiento, ninguna iniciativa se refiere a todos los convenios de la OIT ni a los instrumentos que la organización considera como más actuales. La elección se funda sobre criterios empresariales vinculados a objetivos que no corresponden necesariamente con las finalidades de la institución tripartita. Por consiguiente, los códigos y los criterios de comportamiento varían: dependen de los riesgos y de las preocupaciones propias de cada firma, sin aspirar a la universalidad.

La formulación de estas disposiciones exige reflexión. Algunos documentos consagran reglas específicas o integran instrumentos internacionales precisos, incluso convenios y recomendaciones internacionales del trabajo. En cambio, otras iniciativas se limitan a expresar principios generales sin indicar claramente cómo ponerlas en práctica.

La cuestión del control de la aplicación de las normas elegidas es de larga data. Los procedimientos judiciales y la posible imposición de sanciones - una vez que estas son definidas - suponen que el documento redactado tenga, para el empresario, un valor obligatorio en el sentido jurídico. Si están ausentes, los métodos de evaluación y de seguimiento varían considerablemente. Cabe verificar su seriedad, es decir, a la vez la independencia y las capacidades profesionales de las personas encargadas de la supervisión.

No obstante, la utilidad de estas iniciativas parece generalmente tan reconocida como sus insuficiencias. La RSE apoya y estimula la acción pública; incluso profundiza la realización de sus objetivos ${ }^{47}$. En lo que concierne a las multinacionales, ofrece un cuadro regulador, aunque con un valor jurídico incierto, cuando la ley aplicable o las obligaciones del Estado de acogida en relación con instrumentos internacionales - por ejemplo, los de la OIT — no aparecen con claridad.

Esta tendencia responde a una creciente complementariedad entre las normas de la OIT y las iniciativas sociales de las grandes compañías nacionales y transnacionales que intentan consolidar la protección del trabajo en un espacio jurídicamente gris u oscuro. La imprecisión se debe a la incertidumbre sobre el Derecho nacional aplicable, especialmente cuando las firmas operan en varios países o cuando los estructuras de los Estados interesados son demasiado débiles como para aplicarse normalmente. Procede igualmente del hecho de que las reglas de la OIT no pueden sustituir simple y llanamente las legislaciones desfallecientes para regular relaciones de natura privada.

Tienen, además, sus propias debilidades. En primer lugar, nada o nadie está en la posición de imponer a los Estados la ratificación de un

.


convenio internacional del trabajo, es decir, de comprometerse a observarlas; solo existen excepciones para las disposiciones que figuran en la constitución de la organización, así en materia de libertad sindical o de ausencia de discriminación. Luego, entre los órganos de control, solo la Corte Internacional de Justicia puede formular conclusiones jurídicamente obligatorias, y esta posibilidad nunca fue aprovechada por delegados. La OIT no cuenta con sanciones que conozcan los Derechos nacionales del trabajo en caso de discrepancias.

$\mathrm{Al}$ margen de ello, en todos los casos, incluso cuando se carece de la ratificación que inicia, salvo excepción, el sistema de supervisión de la institución, sus disposiciones y sus principios sirven como apreciable fuente de inspiración no solamente para las autoridades públicas sino también para los actores privados de la escena social. Estas normas, que cubren aproximadamente todos los aspectos del trabajo y de la seguridad social, han demostrado su capacidad de adaptarse a diversos regímenes jurídicos.

Entre los instrumentos de la OIT, interesa destacar la declaración de 1998 relativa a los principios y derechos fundamentales en el trabajo ${ }^{48}$. El documento se focaliza sobre las normas que la organización considera fundamentales: libertad sindical y libre negociación colectiva, no discriminación, eliminación del trabajo forzoso e infantil. Las formula en términos generales, sin entrar en los elementos detallados de su implementación. Su valor imperativo queda limitado y los procedimientos de seguimiento insisten sobre un enfoque promocional y sobre un diálogo interactivo.

En efecto, el texto se dirige principalmente a los Estados miembros, urgidos de tomar medidas de ejecución, pero, a causa de la propia generalidad de su exposición, sirve directamente de referencia para las empresas que redactan su código de conducta o que ponen en marcha otras iniciativas sociales, así como para las sociedades especializadas que definen los criterios que deben respetar las compañías que desean adherirse a su modelo. Hemos aludido a muchos ejemplos.

En estas condiciones, la responsabilidad social de la empresa conlleva un complemento útil a las disposiciones de los Derechos nacionales sobre varios puntos y, más frecuentemente, garantías para su mejor observación. La influencia de la Organización Internacional del Trabajo no es menos significativa por ser limitada. Puede aún crecer. Efectivamente, la OIT continúa poniendo, junto con otras instituciones internacionales, gran empeño en la promoción de sus valores y de las disposiciones que los expresan a través colaboraciones con el sector privado, como lo muestra su última declaración, adoptada en 2008, sobre la justicia social para una globalización equitativa. 